\title{
REGRESSIONAL ESTIMATION OF COTTON SIROSPUN YARN PROPERTIES FROM FIBRE PROPERTIES
}

\author{
Tuba Bedez Üte, Hüseyin Kadoğlu
}

Ege University, Faculty of Engineering, Department of Textile Engineering, Izmir, 35100 Izmir, Turkey

Email: tuba.bedez@ege.edu.tr; huseyin.kadoglu@ege.edu.tr

Abstract:

In this paper, it is aimed at determining the equations and models for estimating the sirospun yarn quality characteristics from the yarn production parameters and cotton fibre properties, which are focused on fibre bundle measurements represented by HVI (high volume instrument). For this purpose, a total of 270 sirospun yarn samples were produced on the same ring spinning machine under the same conditions at Ege University, by using 11 different cotton blends and three different strand spacing settings, in four different yarn counts and in three different twist coefficients. The sirospun yarn and cotton fibre property interactions were investigated by correlation analysis. For the prediction of yarn quality characteristics, multivariate linear regression methods were performed. As a result of the study, equations were generated for the prediction of yarn tenacity, breaking elongation, unevenness and hairiness by using fibre and yarn properties. After the goodness of fit statistics, very large determination coefficients $\left(R^{2}\right.$ and adjusted $\left.R^{2}\right)$ were observed.

\section{Keywords:}

Estimation, HVI, multiple regression analysis, prediction, sirospun system, sirospun yarns, yarn physical properties

\section{Introduction}

Cotton is one of the strategical agricultural products that has various utilization areas in agricultural, industrial and trade sectors. Although the synthetic fibre production is increased in the world, cotton fibre remains important among other raw materials used in the world textile industry (Tables 1 and 2). World's 2012/2013 cotton consumption is forecasted to increase $3.6 \%$ from the last year to 106.9 million bales. China's expected mill use decline will be more than offset by consumption increases in other countries (including Bangladesh, India, Indonesia, Pakistan, Thailand, Turkey and Vietnam).

Table 2. World cotton supply and demand (million tons) [ICAC] [2]

\begin{tabular}{|c|c|c|c|}
\hline & $\mathbf{2 0 1 1 / 2 0 1 2}$ & $\mathbf{2 0 1 2 / 2 0 1 3}$ & $\mathbf{2 0 1 3 / 2 0 1 4}$ \\
\hline $\begin{array}{c}\text { Beginning } \\
\text { stocks }\end{array}$ & 9.60 & 14.05 & 17.00 \\
\hline Production & 27.44 & 26.26 & 22.56 \\
\hline Supply & 37.05 & 40.31 & 39.56 \\
\hline Consumption & 22.78 & 23.31 & 23.79 \\
\hline Exports & 9.93 & 8.30 & 7.93 \\
\hline Ending stocks & 14.05 & 17.00 & 15.77 \\
\hline
\end{tabular}

Table 1. Cotton and man-made staple fibres: mill use on the cotton spinning system (USDA) [1]

\begin{tabular}{|c|c|c|c|c|c|c|}
\hline \multirow{2}{*}{ Year } & \multirow{2}{*}{ Cotton } & \multicolumn{3}{|c|}{ Manmade (staple) } & \multirow{2}{*}{ Total fibres } & \multirow{2}{*}{$\begin{array}{l}\text { Cotton's } \\
\text { percent }\end{array}$} \\
\hline & & Rayon and acetate & Non-cellulosic & Total & & \\
\hline & \multicolumn{5}{|c|}{ 480-Ib bale equivalents } & \\
\hline 1965-1969 & 8.938 .378 & 1.291 .785 & 1.387 .841 & 2.679 .627 & 11.618 .004 & 77 \\
\hline 1970-1974 & 7.496 .527 & 1.012 .476 & 2.408 .645 & 3.421 .121 & 10.917 .647 & 69 \\
\hline 1975-1979 & 6.652 .796 & 755.152 & 3.296 .386 & 4.051 .538 & 10.704 .334 & 62 \\
\hline 1980-1984 & 5.625 .248 & 511.515 & 3.148 .918 & 3.660 .433 & 9.285 .681 & 61 \\
\hline 1985-1989 & 7.604 .683 & 560.667 & 2.987 .151 & 3.547 .818 & 11.152 .501 & 68 \\
\hline 1990-1994 & 10.027.141 & 496.777 & 2.778 .989 & 3.275 .767 & 13.302 .908 & 75 \\
\hline 1995-1999 & 10.743 .448 & 279.625 & 2.661 .284 & 2.940 .909 & 13.684 .357 & 79 \\
\hline $2000-2004$ & 7.357 .521 & 71.382 & 1.644 .424 & 1.715 .806 & 9.288 .685 & 81 \\
\hline 2005-2009 & 4.496 .270 & 18.851 & 750.547 & 769.398 & 5.265 .668 & 86 \\
\hline 2010 & 3.900 .000 & 7.667 & 537.766 & 545.433 & 4.445 .433 & 87,7 \\
\hline 2011 & 3.300 .000 & NA & NA & NA & NA & NA \\
\hline
\end{tabular}

$N A=$ Not available.
Sources: Compiled from reports of the USDC, U.S. Census Bureau and USDA. 
Globalization is growing rapidly; consequently in terms of cotton testing, speaking the same language is becoming more and more important to prevent from ambiguity and misunderstanding. For this purpose, new test methods should be free of variation and human error and should be based on scientific principles, clearly and accurately defined, reproducible and generally accepted [3]. Instead of trusting in the traditional skills of experienced specialist personnel, who have to sort bales according to quality, high volume instrument (HVI) provides rapidly full reports on important quality characteristics including the length, strength, fineness, colour and moisture content of the fibre (Table 3). Subjective assessment of an expert has several disadvantages; it can be highly variable, time-consuming and labour-intensive. Ultimately, as the raw material represents the majority of the yarn production costs of a short-staple yarn, it is critically important to know the desirable fibre characteristics that spinners need for their yarn characteristics and for the selection of the suitable cotton blend.

The spinning consistency index $(\mathrm{SCl})$ is also a regression equation for predicting the spinnability and the overall quality of the cotton fibre. The prediction is based on the average fibre and yarn data taken from USDA (United States Department of Agriculture)'s annual crop reports [5].

As a consequence of quality improvement studies, some of the developments are focused on the ring spinning frame to produce yarns with different structures. Sirospun system is one of these modifications, which is attractive for both long and short staple spinning with improved yarn quality and reduced production costs. For traditional two-plied yarns, twisting binds the surface fibres into the structure of the yarn and makes it more resistant to the abrasive forces that occur during weaving. The sirospun system enables to produce a special spin-twisted yarn directly on a conventional ring spinning machine; consequently, it is the combination of spinning and doubling in the one process. Sirospun yarns are less hairy and more extensible compared with two-plied yarns and have higher tenacity, lower hairiness and better evenness values compared with ring spun yarns with same linear density due to the doubling effect, smaller spinning triangle and well-embedded fibres into the yarn structure [6].

Sirospun spinning system can be installed on conventional ring spinning machine with low investment costs (Figure 2). System provides production increase, lower energy and airconditioning costs, lower production costs, savings on place and staff due to elimination of some processes and avoids possible yarn damages because of transporting materials to those eliminating processes.

\section{Materials and Methods}

To improve yarn quality with respect to customer expectations, modern spinning systems and technological developments, which improve yarn properties, are becoming more important and popular. Nevertheless, previous researches showed that yarn properties are particularly influenced from fibre properties and this effect becomes more influential in the case of finer yarns. If the fibre characteristics are beyond the acceptable limits, it is not possible to produce a good yarn even if we use modern machines and best spinning technologies [7].

In this context, modelling and prediction of the yarn properties have been very attractive for the textile engineers; therefore, several mathematical, statistical and empirical models have

Table 3. Fibre properties measured with HVI (Figure 1) [4].

\begin{tabular}{|c|c|c|c|c|}
\hline \multicolumn{2}{|r|}{ Fibre property } & Abbr. & Unit & Method \\
\hline \multicolumn{2}{|r|}{ Fineness } & MIC & Micronaire & $\begin{array}{l}\text { Measured by relating airflow resistance to the specific surface of } \\
\text { fibres }\end{array}$ \\
\hline \multicolumn{2}{|r|}{ Maturity Index } & MAT & - & $\begin{array}{l}\text { Calculated using an algorithm based on several HVI } \\
\text { measurements }\end{array}$ \\
\hline \multirow{3}{*}{ 莺 } & Upper half mean length & UHML & $\mathrm{mm} / \mathrm{in}$. & \multirow{3}{*}{$\begin{array}{l}\text { Measured optically in a tapered fibre beard, which is automatically } \\
\text { prepared, carded and brushed }\end{array}$} \\
\hline & Uniformity index & UI & $\%$ & \\
\hline & Short fibre Index & SFI & $\%$ & \\
\hline & Strength & STR & g/Tex & \multirow{2}{*}{$\begin{array}{l}\text { Measured physically by clamping a fibre bundle between } 2 \text { pairs } \\
\text { of clamps and pulling away at a constant speed until the fibre } \\
\text { bundle breaks }\end{array}$} \\
\hline & Elongation & ELG & $\%$ & \\
\hline \multicolumn{2}{|r|}{ Moisture Content } & - & - & Measured by using conductive moisture probe \\
\hline \multirow{3}{*}{$\frac{\grave{0}}{\mathrm{O}}$} & Reflectance & Rd & $\%$ & \multirow{3}{*}{$\begin{array}{c}\text { Measured optically by different colour filters, converted to USDA } \\
\text { Upland or Pima Colour Grades or regional customized colour } \\
\text { chart }\end{array}$} \\
\hline & Yellowness & $+\mathbf{b}$ & - & \\
\hline & Colour grade & CG & - & \\
\hline \multirow{3}{*}{ 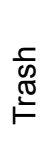 } & Area & - & $\%$ & \multirow{3}{*}{$\begin{array}{l}\text { Measured optically by utilizing a digital camera and converted to } \\
\text { USDA trash grades or customized regional trash standards }\end{array}$} \\
\hline & Trash count & - & - & \\
\hline & Trash grade & - & USDA & \\
\hline \multicolumn{2}{|r|}{ Spin. consistency index } & $\mathrm{SCl}$ & \multicolumn{2}{|c|}{$-414.67+2.9^{\prime} \mathrm{STR}^{\prime}-9.32^{\prime} \mathrm{MIC}+49.17^{\prime} \mathrm{UHML}+4.74^{\prime} \mathrm{UI}+0.65^{\prime} \mathrm{Rd}+0.36^{\prime}(+\mathrm{b})$} \\
\hline \multicolumn{2}{|r|}{ Count strength product } & CSP & \multicolumn{2}{|r|}{ constant $+a{ }^{*} M I C+b{ }^{*} L+c{ }^{*} U I+d{ }^{*} R d+e(+b)+f * E 1+g * S 1$} \\
\hline
\end{tabular}


been developed. These interactions are critically important for the spinners for raw fibre selection. Even though siro spinning method is a modification of ring spinning, they have different spinning geometry, so two methods require different fibre characteristics. Therefore, prediction studies on ring spinning systems are not exactly valid for sirospun yarns. For predicting sirospun yarn characteristics, different cotton blends were selected from different spinning mills in Turkey and their properties were measured with HVI (Figure 1). Yarn count, twist coefficient and strand spacing were also selected as predictors because of their considerable effects on the yarn properties.

Fibre properties were measured with HVI. Sirospun yarn production was carried out on a Rieter G30 ring spinning machine, and for this purpose, the machine was equipped with a sirospun system. This sirospun system was composed of two adjustable roving guides, which are located before break-draft and main-draft zone (Figure 2). In sirospun system, as two rovings were fed through the drafting system, the rovings must be half of the fineness of the rovings that is used to produce ring-spun yarns with same linear density. And this is the point to consider for the production of finer yarns.

All samples were spun into yarns at a yarn count of $\mathrm{Ne} 20$,

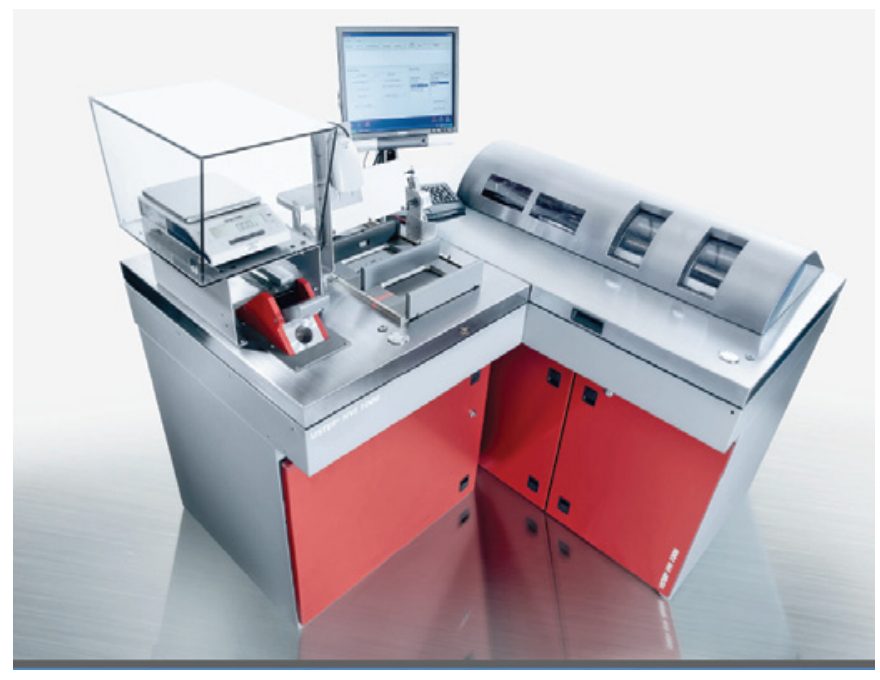

Figure 1. HVI (High volume instrument).

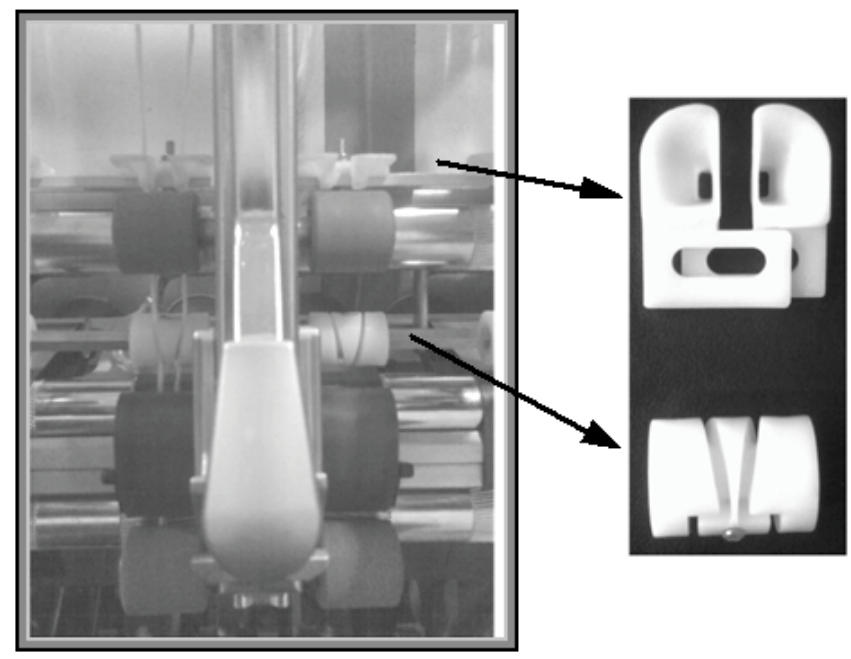

Figure 2. Sirospun system [9].
$\mathrm{Ne} 30, \mathrm{Ne} 40$ and $\mathrm{Ne} 50$. Each yarn count was spun at three different twist multipliers $\left(\alpha_{e} 4, \alpha_{e} 4.5\right.$ and $\left.\alpha_{e} 5\right)$. For each yarn count and twist multiplier, three different strand spacings $(3,6$ and $9 \mathrm{~mm}$ ) were adjusted. Consequently, approximately 270 yarn samples were produced under the same conditions, on the same machine. Appropriate main draft and break draft were adjusted on the ring spinning machine for each sample and other spinning conditions were kept constant. Orbit rings and appropriate travellers for each yarn count were used. For each yarn sample, 10 cops were produced and tested. Experimental plan is given in Figure 3 [8].

Spinning operations can affect fibre properties in different ways, depending on the machinery line and adjustments, etc. For the elimination of these effects, fibre properties were measured using an Uster HVI instrument. The main test results of fibre properties for different blends (from B1 to B11) are given in Table 4.

Yarn unevenness and hairiness tests were performed on an Uster Tester 5, whereas the tensile properties of the yarns were evaluated on an Uster Tensorapid tensile testing machine. Statistical analyses were performed using Minitab and Gretl software.

\section{Results and Discussion}

Regression analysis is a common statistical tool for the investigation of relationships between two groups of variables. The fitted model can be used to describe the relationship between dependent and independent variables, or also to predict new values. Yarn characteristics are influenced by several factors such as fibre properties, production parameters, machine settings, the spinning conditions, etc. For this reason, the multiple regression analysis and ordinary least-squares methods were selected to learn the relationship between independent (predictor) variables and a dependent (criterion) variable. The types of relationship between independent variables (selected parameters) and dependent variables (yarn properties) were checked by using curve estimation and correlation analysis. Statistical analysis demonstrated that there was a nearly linear relationship between fibre properties measured with $\mathrm{HVI}$ and sirospun yarn properties. Because of this, the linear multiple regression analysis method was chosen for this study [10].

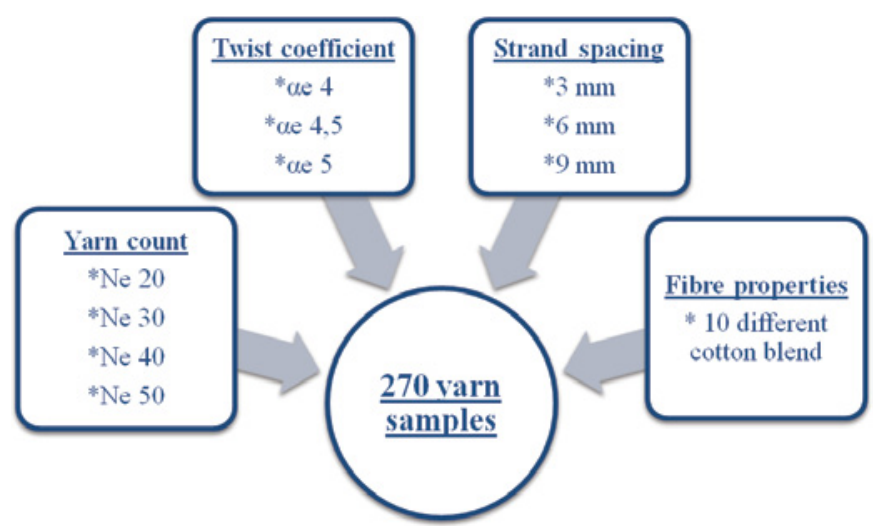

Figure 3. Experimental plan. 
Table 4. Fibre properties measured with HVI.

\begin{tabular}{|c|c|c|c|c|c|c|c|c|c|c|c|}
\hline & B1 & B2 & B3 & B4 & B5 & B6 & B7 & B8 & B9 & B10 & B11 \\
\hline $\begin{array}{c}\text { MIC } \\
\text { (micronaire) }\end{array}$ & 5 & 5 & 5 & 4.8 & 5.1 & 5 & 4.6 & 5.2 & 5.2 & 5.3 & 5 \\
\hline STR (gr/tex) & 45.5 & 41.5 & 43.3 & 47.2 & 35.8 & 36.8 & 34.6 & 36.8 & 36.3 & 38 & 39 \\
\hline LEN (mm) & 33.6 & 33.1 & 30.3 & 36.3 & 30 & 31.4 & 29.7 & 31 & 29.4 & 32.6 & 31.1 \\
\hline UNF (\%) & 88.2 & 88.2 & 86.7 & 89.2 & 86.9 & 86.4 & 85 & 86.8 & 85.4 & 87.2 & 86.6 \\
\hline SFI (\%) & 8.2 & 11.4 & 12.3 & 8.2 & 10 & 10 & 11.7 & 8.2 & 12.5 & 11.7 & 10.8 \\
\hline ELG (\%) & 4.8 & 5.6 & 5.4 & 4.8 & 5.5 & 4.5 & 5.8 & 5.3 & 4.1 & 4.5 & 5.4 \\
\hline MAT (\%) & 90 & 89 & 89 & 89 & 89 & 89 & 87 & 89 & 90 & 90 & 89 \\
\hline SCI & 214 & 196 & 194 & 227 & 170 & 174 & 163 & 173 & 162 & 183 & 182 \\
\hline CSP & 2553 & 2362 & 2427 & 2547 & 2235 & 2342 & 2318 & 2287 & 2242 & 2436 & 2357 \\
\hline CG & $11-2$ & $32-1$ & $21-1$ & $13-2$ & $12-1$ & $21-4$ & $11-2$ & $11-4$ & $21-3$ & $11-2$ & $11-4$ \\
\hline Rd (\%) & 80.4 & 73.4 & 80.7 & 75 & 78.8 & 77.4 & 80.1 & 78.3 & 78.5 & 81.4 & 79.5 \\
\hline +b & 9.2 & 10.5 & 8.5 & 11,5 & 11,5 & 9 & 9.2 & 10.5 & 9.4 & 8.9 & 10 \\
\hline
\end{tabular}

Among fibre properties, it is found that there is a high correlation between mean fibre length and uniformity index (Pearson correlation coefficient $=0.924$, Table 5). For regression estimation, the independent variables that have a higher correlation with dependent variables (fibre length have a higher correlation with yarn properties than uniformity index) have been used. Besides, fibre fineness, strength, elongation, short fibre index, yellowness, reflectance and maturity index values were taken into account (Table 6). SCI and CSP were not used as they are already regression expressions and colour grade was not used as it is not a numerical value.

The relations between yarn properties and predictors were analysed individually by curve estimation. First, collinearity was tested and an exact relationship between some variables was found with correlation analysis. After that,

Table 5. Pearson correlation coefficients between fibre properties measured with HVI.

\begin{tabular}{|c|c|c|c|c|c|c|c|c|c|}
\hline & MIC & STR & LEN & UNF & SFI & ELG & Rd & +b & MAT \\
\hline MIC & 1 & $-0.521^{* *}$ & $-0.417^{* *}$ & $-0.357^{* *}$ & $0.336^{* *}$ & $-0.354^{* *}$ & $0.449^{* *}$ & $-0.309^{* *}$ & $0.642^{* *}$ \\
\hline STR & $-0.521^{* *}$ & 1 & $0.855^{* *}$ & $0.851^{* *}$ & $-0.487^{* *}$ & -0.008 & $-0.273^{* *}$ & $0.135^{* *}$ & $0.174^{* *}$ \\
\hline LEN & $-0.417^{* *}$ & $0.855^{* *}$ & 1 & $0.924^{* *}$ & $-0.508^{* *}$ & $-0.088^{* *}$ & $-0.382^{* *}$ & $0.235^{* *}$ & $0.126^{* *}$ \\
\hline UNF & $-0.357^{* *}$ & $0 . .851^{* *}$ & $0.924^{* *}$ & 1 & $-0.550^{* *}$ & $0.159^{* *}$ & $-0.436^{* *}$ & $0.411^{* *}$ & $0.112^{* *}$ \\
\hline SFI & $0.336^{* *}$ & $-0.487^{* *}$ & $-0.508^{* *}$ & $-0.550^{* *}$ & 1 & $-0.091^{* *}$ & $0.095^{* *}$ & $-0.394^{* *}$ & $0.058^{* *}$ \\
\hline ELG & $-0.354^{* *}$ & -0.008 & $-0.088^{* *}$ & $0.159^{* *}$ & $-0.091^{* *}$ & 1 & $-0.302^{* *}$ & $0.494^{* *}$ & $-0.69^{* *}$ \\
\hline Rd & $0.449^{* *}$ & $-0.273^{* *}$ & $-0.382^{* *}$ & $-0.436^{* *}$ & $0.095^{* *}$ & $-0.302^{* *}$ & 1 & $-0.593^{* *}$ & $0.396^{* *}$ \\
\hline +b & $-0.309^{* *}$ & $0.135^{* *}$ & $0.235^{* *}$ & $0.411^{* *}$ & $-0.394^{* *}$ & $0.494^{* *}$ & $-0.593^{* *}$ & 1 & $-0.41^{* *}$ \\
\hline MAT & $0.642^{* *}$ & $0.174^{* *}$ & $0.126^{* *}$ & $0.112^{* *}$ & $0.058^{* *}$ & $-0.688^{* *}$ & $0.396^{* *}$ & $-0.407^{* *}$ & 1 \\
\hline
\end{tabular}

${ }^{* *}$ Correlation is significant at 0.01 level (two-tailed).

Table 6. Pearson correlation coefficients between dependent and independent variables.

\begin{tabular}{|c|c|c|c|c|c|}
\hline \multirow{4}{*}{$\frac{5}{\frac{5}{\pi}}$} & & Yarn evenness & Yarn hairiness & Yarn tenacity & Breaking elongation \\
\hline & $\mathrm{SS}(\mathrm{mm}) 1$ & -0.018 & $-0.150^{* *}$ & $0-.003$ & 0.035 \\
\hline & YC (Ne) 2 & $0.815^{* *}$ & $-0.835^{* *}$ & $-0.130^{\star *}$ & $-0.629^{* *}$ \\
\hline & ae3 & $-0.159^{* *}$ & -0.013 & $0.27^{* *}$ & $0.602^{* *}$ \\
\hline \multirow{8}{*}{ 은 } & MIC & -0.003 & $-0.135^{* *}$ & $-0.216^{* *}$ & $-0.106^{* *}$ \\
\hline & STR & $-0.198^{\star *}$ & $-0.284^{* *}$ & $0.734^{* *}$ & -0.032 \\
\hline & LEN & $-0.187^{* *}$ & $-0.401^{* *}$ & $0.768^{* *}$ & -0.024 \\
\hline & SFI & $0.084^{* *}$ & $0.248^{* *}$ & $-0.425^{\star *}$ & $-0.075^{* *}$ \\
\hline & ELG & $0.163^{* *}$ & $0.211^{* *}$ & $-0.353^{* *}$ & $0.206^{* *}$ \\
\hline & $\mathbf{R d}$ & 0.012 & $0.117^{* *}$ & $-0.041^{\star}$ & 0.011 \\
\hline & $+b$ & $0.045^{*}$ & $-0.080^{* *}$ & -0.0235 & $0.095^{\star \star}$ \\
\hline & Mat & $-0.165^{\star *}$ & $-0.391^{* *}$ & $0.423^{* *}$ & $-0.203^{\star *}$ \\
\hline
\end{tabular}

${ }^{1}$ SS: Strand spacing; ${ }^{2}$ YC: Yarn count; ${ }^{3} \alpha_{e}$ :Twist coefficient

" Correlation is significant at 0.05 level (two-tailed). ${ }^{* *}$ Correlation is significant at 0.01 level (two-tailed). 
Best Subsets Regression method was used for determining which independent variables should be included in a multiple regression model. Subsequently, the relations between yarn properties and determined predictors were analyzed one by one by curve estimation and some quadratic or polynomial relations were found with some fibre properties.

Stepwise regression was used to control the details of the process. Models having higher adjusted $R^{2}$, but lower Akaike and Schwarz values were chosen. Lastly, White test was applied for seeking if there is a heteroscedasticity in the regression model and establish whether the residual variance of a variable in the regression model is constant. The possible existence of heteroscedasticity can invalidate statistical tests of significance that assume that the modelling errors are uncorrelated and normally distributed and that their variances do not vary with the effects being modelled.
Even if White test's results showed that there is a heteroscedasticity in regression model, a new model was established to solve this problem. Final regression coefficients of variables, $t$-values and significance level of each variable of the new model are given in Tables 7-10. Regression coefficients, given in the tables, are the constants, which represent the rate of change of a dependent variable (e.g. yarn property) as a function of changes in the independent variable (e.g. fibre property). P-value is used for determining statistically significance, the $t$-ratio is a ratio of the departure of an estimated parameter from its notional value and its standard error [11].

The regression coefficients of the predictor variables were found statistically significant. Signs (+ or -) of regression coefficients of variables indicate the direction of influence.

Table 7. Regression coefficients, $t$-values and significance level of $t$-values of linear regression model for yarn unevenness.

\begin{tabular}{|c|c|c|c|c|c|c|c|c|c|c|c|c|}
\hline & Constant & $\begin{array}{c}\text { SS } \\
(\mathrm{mm})\end{array}$ & $\begin{array}{l}\text { YC } \\
(\mathrm{Ne})\end{array}$ & $\begin{array}{c}\text { TC } \\
\text { (ae) }\end{array}$ & MIC & STR & LEN & SFI & ELG & Rd & $+b$ & MAT \\
\hline Coefficient & 150.186 & 0.028 & 0.176 & 0.108 & 1.487 & 0.105 & -0.362 & 0.073 & -0.41 & 0.066 & 0.089 & -1.677 \\
\hline Std. error & 5.563 & 0.004 & 0.001 & 0.021 & 0.254 & 0.014 & 0.015 & 0.009 & 0.039 & 0.007 & 0.022 & 0.075 \\
\hline$t$-ratio & 26.996 & 7.621 & 155.868 & 5.174 & 5.862 & 7.277 & -23.789 & 7.630 & -10.310 & 9.758 & 4.079 & -22.445 \\
\hline$p$-value & 0.000 & 0.000 & 0.000 & 0.000 & 0.000 & 0.000 & 0.000 & 0.000 & 0.000 & 0.000 & 0.000 & 0.000 \\
\hline
\end{tabular}

Table 8. Regression coefficients, $t$-values and significance level of $t$-values of linear regression model for yarn hairiness.

\begin{tabular}{|c|c|c|c|c|c|c|c|c|c|c|c|c|c|}
\hline & Constant & $\begin{array}{c}\text { SS } \\
(\mathrm{mm})\end{array}$ & $\begin{array}{l}\mathrm{YC} \\
(\mathrm{Ne})\end{array}$ & $\begin{array}{c}\text { TC } \\
\text { (ae) }\end{array}$ & MIC & MIC2 & MIC3 & STR & ELG & LEN & SFI & MAT & $+b$ \\
\hline Coefficient & -768.443 & -0.069 & -0.054 & -0.221 & 99.12 & -103.95 & 7.194 & 0.06 & 0.07 & -0.201 & 0.01 & -0.18 & -0.04 \\
\hline Std. error & 234.026 & 0.002 & 0.001 & 0.01 & 141.38 & 28.51 & 1.913 & 0.01 & 0.02 & 0.009 & 0.004 & 0.03 & 0.01 \\
\hline$t$-ratio & -3.284 & -40.26 & -113.3 & -23.23 & 3.53 & -3.65 & 3.76 & 11.1 & 3.04 & -21.12 & 2.83 & -5.65 & -6.73 \\
\hline$p$-value & 0.001 & 0.00 & 0.00 & 0.00 & 0.00 & 0.00 & 0.0001 & 0.00 & 0.002 & 0.000 & 0.005 & 0.00 & 0.00 \\
\hline
\end{tabular}

Table 9. Regression coefficients, $t$-values and significance level of $t$-values of linear regression model for yarn tenacity.

\begin{tabular}{|c|c|c|c|c|c|c|c|c|c|c|c|}
\hline & Constant & $\begin{array}{c}\text { SS } \\
\mathbf{( m m})\end{array}$ & $\begin{array}{c}\text { YC } \\
\mathbf{( N e )}\end{array}$ & $\begin{array}{c}\text { TC } \\
\mathbf{( a e )}\end{array}$ & $\mathbf{S T R}$ & LEN & ELG & ELG2 & MAT & Rd & SFI \\
\hline Coefficient & -81.972 & -0.022 & -0.111 & 1.132 & 0.065 & 1.358 & -51.819 & 5.239 & 1.856 & 0.294 & -0.699 \\
\hline Std. error & 5.256 & 0.008 & 0.002 & 0.0445 & 0.009 & 0.024 & 2.114 & 0.217 & 0.054 & 0.013 & 0.023 \\
\hline$t$-ratio & -155.96 & -26.76 & -528.17 & 254.53 & 66.80 & 569.76 & -245.13 & 241.54 & 342.29 & 234.18 & -309.22 \\
\hline$p$-value & 0.000 & 0.007 & 0.000 & 0.000 & 0.000 & 0.000 & 0.000 & 0.000 & 0.000 & 0.000 & 0.000 \\
\hline
\end{tabular}

Table 10. Regression coefficients, $t$-values and significance level of $t$-values of linear regression model for yarn elongation.

\begin{tabular}{|c|c|c|c|c|c|c|c|c|c|c|c|}
\hline & Constant & $\begin{array}{c}\text { SS } \\
(\mathbf{m m})\end{array}$ & $\begin{array}{c}\text { YC } \\
\mathbf{( N e )}\end{array}$ & $\begin{array}{c}\text { TC } \\
(\mathbf{\alpha e})\end{array}$ & MIC & STR & ELG & LEN & SFI & MAT & Rd \\
\hline Coefficient & -15.789 & 0.012 & -0.036 & 0.752 & -0.483 & -0.047 & 0.389 & 0.069 & -0.042 & 0.208 & 0.016 \\
\hline Std. error & 2.846 & 0.003 & 0.001 & 0.016 & 0.132 & 0.005 & 0.024 & 0.008 & 0.006 & 0.038 & 0.003 \\
\hline$t$-ratio & -5.548 & 4.256 & -45.773 & 48.468 & -3.662 & -9.157 & 15.982 & 8.960 & -7.525 & 5.480 & 4.818 \\
\hline$p$-value & 0.000 & 0.000 & 0.000 & 0.000 & 0.000 & 0.000 & 0.000 & 0.000 & 0.000 & 0.000 & 0.000 \\
\hline
\end{tabular}


According to Table 7, it is found that yarn unevenness increases with the increasing of the yarn count $(\mathrm{Ne})$, twist coefficient and strand spacing. Fibre maturity and evenness are most important fibre properties for yarn unevenness. Yarn unevenness increases with the increase in fibre strength, short fibre index, yellowness, brightness, but decreases by using finer, mature and longer fibres having higher breaking elongation values.

Table 8 shows that yarn hairiness decreases with the increasing yarn fineness, twist coefficient and strand spacing, as expected. It is found that fibre maturity, fineness and length parameters are the most effective fibre properties on yarn hairiness, due to their higher regression coefficients. As long as fibre strength, elongation and short fibre index decrease, whereas fibre length, maturity and brightness increase, yarn hairiness decreases. Fibre fineness has a polynomial relation with yarn hairiness, so, yarn hairiness significantly increases with the increase of micronaire value, after that hairiness decreases, then increases again.

It is found that yarn strength decreases with the increasing yarn count $(\mathrm{Ne})$ and strand spacing whereas decreasing the twist coefficient, as expected. Among fibre properties measured with $\mathrm{HVI}$, mean fibre length, elongation and maturity are the main parameters influencing the yarn strength. Increased fibre length and maturity have increased yarn strength, whereas increased short fibre content has decreased yarn strength (Table 9). A quadratic relation between fibre elongation and yarn strength was found. Initially, yarn strength decreases with the increasing fibre elongation, up to a limit, afterwards the increase in the fibre elongation causes an increase in the yarn strength [12].

According to Table 10, the most important fibre properties measured with $\mathrm{HVI}$ for breaking elongation are fibre elongation, fineness and maturity, respectively. Yarn production parameters have significant effect on breaking elongation.

Figure 4 shows the scatter plot of predicted values versus actual values and regression line of the four models. A high correlation $(r)$ was found between actual and predicted values $\left(r_{\text {(yarn unevenness) }}=0.95, r_{\text {(yarn hairness) }}=0.95, r_{\text {(yarn tenacity) }}=0.96, r_{\text {(yarn }}\right.$ elongation) $=0.84$ ).

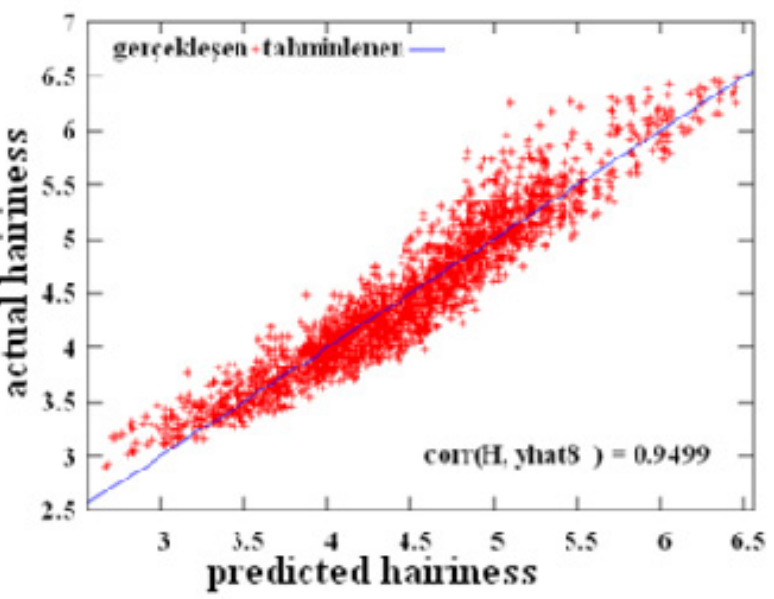

(b)

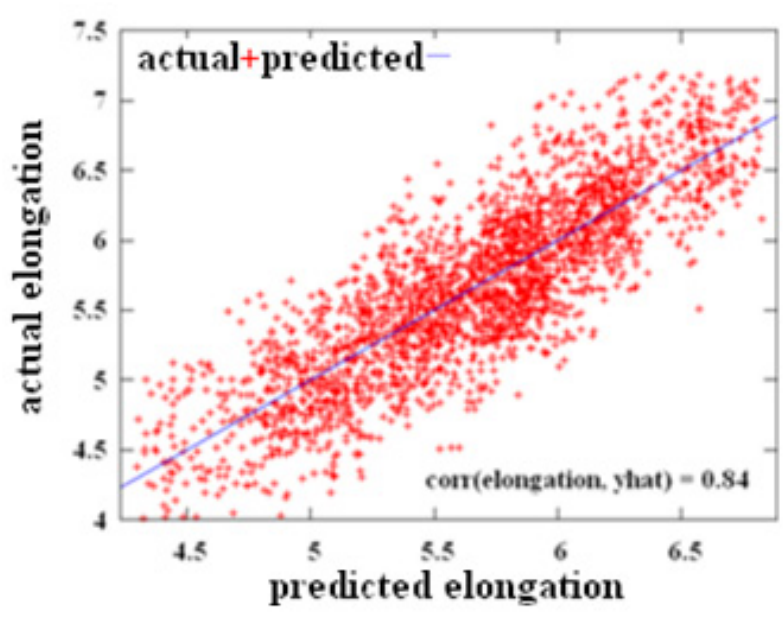

(d)

Figure 4. Predicted versus actual values of (a) yarn evenness, (b) yarn hairiness, (c) yarn tenacity and (d) breaking elongation values. 


\section{Conclusion}

In this study, we have tried to predict cotton sirospun yarn properties such as yarn evenness, yarn hairiness, yarn tenacity and breaking elongation by using fibre properties measured with HVI with linear multiple regression analysis. It is found that, uniformity index was highly correlated with mean fibre length, and fibre length has a higher correlation with yarn properties than uniformity index; thus, uniformity index was not used. Besides, SCl and CSP were not used as they are already regression expressions and colour grade was not used as it is not a numerical value. In conclusion, fibre length, fibre fineness, strength, elongation, short fibre index, yellowness, reflectance and maturity index values were taken into account.

Final regression equations obtained after several analyses are represented all together in Table 11. Adjusted $R^{2}$ is used to measure the goodness of fit in the models and statistical evaluation showed that our equations had very large $R^{2}$ and adjusted $R^{2}$ values.
It is seen that the most important fibre properties influencing yarn evenness and hairiness are fibre maturity and fineness, respectively, due to their high regression coefficients. For hairiness, fibre length is also very important. In terms of higher yarn tenacity, spinners are recommended to select raw materials primarily having higher fibre length and higher maturity ratio. On the other hand, if breaking elongation is more important, they have to select materials having higher elongation, maturity and micronaire values. Although spinners have to take into consider that, yarn count, twist coefficient and strand spacing values have significant effects on yarn characteristics.

\section{Acknowledgements}

The authors express their thanks to the Republic of Turkey, Ministry of Science, Industry and Technology and Söktaş for supporting this research.

Table 11. Regression equations and $R^{2}$ values for yarn properties.

\begin{tabular}{|c|c|c|c|}
\hline Yarn property & Regression equation & $\mathrm{R} 2$ & Adj. R2 \\
\hline $\begin{array}{l}\text { Yarn unevenness } \\
\quad(\mathrm{CV} \%)\end{array}$ & $\begin{array}{l}\text { 150.186 + 0.028 SS + 0.176 Yarn count }(\mathrm{Ne})+0.108\left(\alpha_{\mathrm{e}}\right)+1.487 \mathrm{MIC}+0.105 \\
\text { STR }-0.362 \mathrm{LEN}+0.073 \mathrm{SFI}-0.41 \mathrm{ELG}+0.066 \mathrm{Rd}+0.089 \mathrm{~b}-1.677 \mathrm{Mat}\end{array}$ & 0.92 & 0.92 \\
\hline Yarn hairiness $(\mathrm{H})$ & $\begin{array}{c}-768.443-0.069 \mathrm{SS}^{*}-0.054 \text { Yarn count }(\mathrm{Ne})-0.221\left(\alpha_{\mathrm{e}}\right)+409.118 \mathrm{MIC}- \\
103.954 \mathrm{Mic}^{2}+7.194 \mathrm{Mic}^{3}+0.056 \mathrm{STR}+0.067 \mathrm{ELG}-0.201 \mathrm{LEN}+0.012 \mathrm{SFI}- \\
0.039 \mathrm{~b}-0.179 \mathrm{Mat}\end{array}$ & 0.91 & 0.91 \\
\hline $\begin{array}{l}\text { Yarn tenacity }(\mathrm{cN} / \\
\text { tex })\end{array}$ & $\begin{array}{c}-81.972-0.022 \mathrm{SS}^{*}-0.111 \text { Yarn count }(\mathrm{Ne})+1.132\left(\alpha_{e}\right)+0.065 \mathrm{Str}+1.358 \text { Len }- \\
51.82 \mathrm{Elg}+5.24 \mathrm{Elg}^{2}+1.86 \mathrm{Mat}+0.29 \mathrm{Rd}-0.69 \mathrm{SFI}\end{array}$ & 0.90 & 0.90 \\
\hline $\begin{array}{l}\text { Breaking } \\
\text { elongation (\%) }\end{array}$ & $\begin{array}{c}-15.789+0.012 \text { SS }^{*}-0.036 \text { Yarn count }(\mathrm{Ne})+0.752\left(\alpha_{\mathrm{e}}\right)-0.483 \mathrm{MIC}-0.047 \mathrm{STR} \\
+0.389 \mathrm{ELG}+0.069 \mathrm{LEN}-0.042 \mathrm{SFI}+0.208 \mathrm{Mat}+0.016 \mathrm{Rd}\end{array}$ & 0.71 & 0.71 \\
\hline
\end{tabular}

* SS: Strand spacing.

\section{References}

[1] USDA, Cotton and Wool Yearbook, http://www.ers.usda. gov/data-products/cotton,-wool,-and-textile-data/cottonand-wool-yearbook.aspx, (2012 accessed 5 September 2013)

[2] ICAC-International Cotton Advisory Committee, Cotton This Month, (2013, accessed 1 March 2013.

[3] Hunter L., HVI Testing of Cotton: Its Present Status and Future Prospects, 26th International Cotton Conference Bremen, 16 March 2002.

[4] http://www.uster.com/en/instruments/ginning-cottonclassing/uster-hvi/ (Accessed 5 September 2013)

[5] Majumdar A., Majumdar P. K., Sarkar B., "Selecting Cotton Bales By Spinning Consistency Index and Micronaire Using Artificial Neural Networks", AUTEX Research Journal, 2004, 4: 1, March, http://www.autexrj.org/No1-2004/0092. pdf , (2004, accessed 1 March 2013)

[6] Bedez Ute T., Research On Spinning of Short Staple Fibres by Sirospun System, Ege University Graduate School of Natural and Applied Sciences, Master of Science Thesis, 2007.
[7] Schneider U., Uster Quantum 2, Application Report, Current trends to improve the yarn quality in spinning mills, The Yarn Quality Assurance System, http://www.uster. com/fileadmin/customer/Knowledge/Textile_Know_How/ Yarn_clearing/UQ2_Current_trends_to_improve_the_ yarn.p.pdf, (2008, accessed 1 March 2013)

[8] Bedez Ute T., Kadoglu H., Regressional Estimation of Yarn Hairiness of Cotton Sirospun Yarns From AFIS Fibre Properties, ITC\&DC-International Textile, Clothing \& Design Conference, 7-10 2012, Dubrovnik, Croatia.

[9] Parthasarath, V., Evolution in cotton testing instruments, The Indian Textile Journal April 2008.

[10] Ureyen M.E. and Kadoğlu H.: Regressional Estimation of Ring Cotton Yarn Properties from HVI Fibre Properties, Textile Research Journal, 2006, 76: p360.

[11] http://en.wikipedia.org/wiki/T-statistic\#Definition, (2011, accessed 4 September 2013).

[12] Ureyen, M. E., and Kadoğlu H., 2007, "The Prediction of Cotton Ring Yarn Properties from AFIS Fibre Properties by Using Linear Regression Models", Fibres \& Textiles in Eastern Europe, 2007 :15, No. 4, p 63. 